\title{
Rumo à América: passageiros da rota Hamburgo-São Francisco do Sul na segunda metade dos Oitocentos ${ }^{\star}$
}

\author{
Sergio Odilon Nadalin ${ }^{\star \star}$
}

0 presente texto tem como objetivo apresentar criticamente um conjunto de documentos que dizem respeito à e/imigração. Trata-se de listas de passageiros embarcados em Hamburgo e desembarcados em São Francisco do Sul, Santa Catarina, entre 1851 e 1889, traduzidas para 0 português, cujos originais fazem parte do acervo do Arquivo Histórico de Joinville, Santa Catarina. Basicamente, o conteúdo destas fontes inclui as "fichas técnicas" referentes a cada navio e à viagem relacionada, os nomes dos passageiros (constando ou não o nome dos familiares e outros acompanhantes), a idade, profissão, proveniência (geralmente local de origem), estado civil (quando era o caso), religião e observações diversas anotadas pelos tradutores.

Palavras-chave: História das migrações. Fontes. Imigração alemã. Colonização.

\footnotetext{
* Comunicação apresentada no XXI Encontro Nacional de Estudos Populacionais, realizado de 22 a 28 de setembro de 2018, em Poços de Caldas, MG.

** Universidade Federal do Paraná (UFPR), Curitiba-PR, Brasil (sergion@terra.com.br; https://orcid.org/0000-0001-50912241).
} 


\section{À guisa de introdução, a saga dos Hering em Blumenau}

Hermann Hering embarcou em Hamburgo no vapor "Rio", ${ }^{1}$ em 5 de setembro de 1878. Na lista de passageiros, informou sua idade (43 anos), ocupação (“tecelão de meias"), origem (Dresden, Saxônia), estado civil (solteiro [sic]), religião (protestante) e tipo de passagem ( $3^{a}$ classe). Pertencente a uma longa linhagem de tecelões, que remonta ao século XVII, Hermann decidiu emigrar por causa da situação econômica e social que se abatera sobre a Europa. 0 recém-chegado foi para a Colônia Blumenau, atuando como guarda-livros de comerciantes locais. Em seguida, investiu em um "bar", incluindo uma manufatura de charutos, e logo partiu para novos empreendimentos, o que the permitiu amealhar recursos para fazer vir da Saxônia seus dois filhos adolescentes, Paul e Elise. ${ }^{2}$

Assim, Paul Hering embarcou em Hamburgo no vapor "Montevideo", no dia 18 de julho de 1879; foi registrado com a idade de 17 anos como pintor (ou lavrador, de acordo com a lista dos imigrantes, aberta na Colônia Dona Francisca). Era solteiro e também natural de Dresden. Acompanhava-o sua irmã Elise, com 14 anos, ambos protestantes como o pai. Chegaram em São Francisco do Sul (Santa Catarina) em 18 de agosto de 1879.

Foi mais ou menos nessa ocasião que o pai decidiu investir suas economias num tear e em matéria-prima, voltando-se para a especialidade de sua linhagem. 0 negócio familiar prosperou e, assim, finalmente, puderam vir da Alemanha sua esposa e filhos, ${ }^{3}$ acompanhando o irmão Bruno,embarcando em Hamburgo no mesmo "Montevideo", quase umano depois, em 18 de junho de 1880. 0 navio fundeou na baía de São Francisco em 19 de julho, após escalas em Lisboa, Bahia, Rio de Janeiro e Santos.

\section{0 contexto}

A documentação original em referência neste texto foi produzida no âmbito dos deslocamentos de populações característicos da segunda metade do século XIX e início do XX. Neste quadro, cerca de 40 milhões de europeus abandonaram definitivamente o continente de 1800 a 1930, entre eles os alemães que, depois de 1846, partiam em quantidades cada vez maiores, chegando de 50 a 100 mil indivíduos por ano, com um máximo de aproximadamente 220 mil entre 1880 e $1885 .{ }^{4}$ Sintetizando, cerca de 6 milhões de alemães emigraram desde 1820 (REINHARD; ARMENGAUD; DUPÂQUIER, 1968, p. 395-400).

\footnotetext{
${ }^{1}$ Registre-se que o último navio a velas que fazia a rota Hamburgo-São Francisco do Sul foi o "Humbolt”, de 741 toneladas inglesas. Partiu em 15/04/1876 e chegou em 11/06/1876 - a viagem durou, portanto, praticamente dois meses, contando escalas (não anotadas). Os navios a vapor, que se seguiram, faziam a viagem em mais ou menos um mês. A respeito das questões relacionadas às transformações quanto à utilização dos navios a vela e dos navios a vapor, ver Leite (1991).

2 Os dados biográficos de Hermann e Bruno Hering, fundadores das Indústrias Hering em Santa Catarina, foram obtidos em Malheiros (2011, p. 38-39).

${ }^{3}$ Na lista do "Rio", Hermann foi registrado como "solteiro", erro possível nas listas.

${ }^{4}$ Neiva e Carneiro (1950, p. 60-61) organizaram um quadro dispondo as estatísticas de ingressos anuais no Brasil entre 1819 e 1947, somando 4.635.890 imigrantes europeus. Este total não inclui japoneses e sírio-libaneses, mas existem 347.384 indivíduos relativos à coluna dos "diversos".
} 
Estas grandes migrações estão associadas a rupturas estruturais tanto nos "países novos" como nos países emissores - ou seja, as motivações americanas e europeias que alavancaram as migrações faziam parte de um mesmo processo, cuja origem radicava-se na Europa. De um lado, havia um conjunto complexo de mudanças que desembocaram nos séculos XIX e XX e que, de forma generalizada, tomam o nome de transição demográfica. Estas transformações na população europeia articulavam-se de modo contraditório às inércias que sustentavam as sociedades camponesas naquele continente, fruto de uma longa história suportada por uma "economia moral”, caracteristicamente comunitária e local. A esse quadro correspondia uma população quase estacionária, com altos índices de mortalidade e natalidade.

Este mundo conservador tinha como contraponto as profundas mudanças ocorridas com a expansão do capitalismo, as quais, em diversos momentos, estavam estreitamente ligadas às transformações sociodemográficas. Estas alterações geraram excedentes populacionais que, dependendo da conjuntura local e de fatores culturais, levavam a uma maior ou menor predisposição às migrações e, por extensão, à emigração transoceânica. Na época moderna assiste-se, igualmente, à gradativa fusão das inúmeras unidades econômicas - até então fechadas em si mesmas - em grandes mercados regionais e, mesmo, à constituição de mercados internacionais. Essas ocorrências foram acompanhadas pelo fortalecimento de uma mentalidade individualista, que de maneira paulatina também contribuiu para - e foi simultaneamente consequência - o desenraizamento da população do campo e das pequenas unidades urbanas, em parte direcionada para as migrações a longa distância.

Enfim, estes deslocamentos populacionais, na medida em que estamos tratando do fenômeno de expansão capitalista, acompanharam o processo de transferências de capitais para os "países novos" e as "colônias". Processos igualmente casados, pois a migração de capitais gerava a necessidade da transformação da mão de obra para fecundar este capital e permitir que ele se multiplicasse. Dito de outra maneira, embora ainda reforçando esta perspectiva da história econômica: num nível de análise mais amplo, as grandes migrações do século passado podem ser situadas nas acomodações necessárias para o pleno desenvolvimento do capitalismo, desempenhando, inclusive, papel decisivo para seu fortalecimento numa escala mundial. É nesse contexto que, para regular o destino dos emigrantes, companhias particulares de colonização foram criadas, como foi o caso da "Sociedade Colonizadora de 1849", sediada em Hamburgo. Foi também assim que se desenvolveram companhias de navegação, notadamente sediadas nesta cidade e em Bremen, que, entre outras funções, organizaram o transporte de emigrados que afluíam de toda a Europa central e oriental para a travessia do Atlântico. De fato, "nas cidades hanseáticas, a emigração foi encarada principalmente sob aspectos econômicos. Bremen, de início o principal porto de emigração para o Brasil, inclinou-se nos anos 40 para a emigração para a América do Norte” (REINHARD; ARMENGAUD; DUPÂQUIER, 1968, p. 400). Hamburgo tomou o seu lugar: as pesquisas de Jürgen Schneider (1980, p. 92) em 
arquivos alemães contabilizaram, de 1847 a 1870, 286 navios trazendo 30.795 imigrantes desembarcados no Brasil. ${ }^{5}$

Portanto, transição demográfica, expansão capitalista (e uma revolução tecnológica na navegação) e grandes migrações são processos interligados igualmente no espaço. As diversas ondas emigratórias europeias, que atingiram o apogeu na passagem do século e retomaram com outras características no período entre guerras, acompanharam com relativa coerência o avanço da transição demográfica e do capitalismo, expandindo-se sucessivamente do noroeste para o sul e leste europeus.

Diríamos, assim, que essa visão multilateral privilegia o entendimento do processo de transferência populacional, incluindo ainda o fato de que ao mecanismo de repulsão que se processou na Europa correspondeu um processo de atração de imigrantes na América, não como uma coincidência fortuita, mas sim no quadro da divisão internacional do trabalho. Isso porque, desse lado do Atlântico, construía-se uma nova sociedade na qual o imigrante era extremamente necessário, o que se justificava com argumentos deduzidos da ideologia liberal do século XIX.

\section{As listas de passageiros}

As listas aqui referidas correspondem aos passageiros que embarcaram em Hamburgo ${ }^{6}$ (sede da Companhia Colonizadora de Hamburgo, fundada em 1849) e desembarcaram em São Francisco do Sul - de onde partiriam para Dona Francisca ${ }^{7}$ e/ou outras colônias, localizadas mais para o interior de Santa Catarina. Não se trata das listas originais, mas sim fruto da versão em português transcrita por Elly Herkenhoff e Maria Tereza Böbel, publicadas na internet. ${ }^{8}$ Para alguns casos, desconfia-se de problemas na tradução e cópia (por exemplo, aparente ilegibilidade de nomes próprios, de locais de origem, etc.). Todavia, a grande vantagem desse exaustivo trabalho, iniciado em 1982 e completado em 2010, sem mencionar a facilidade de acesso e de leitura aos pesquisadores, é que as listas de embarque foram comparadas com os róis de desembarque, e os resultados

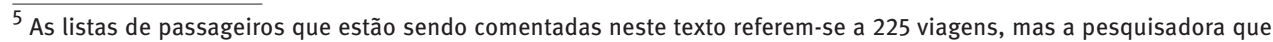
publicou a documentação ressalva que não conseguiu notícias sobre todos os navios que aportaram em São Francisco do Sul (BÖBEL, 2001, p. 14).

${ }^{6}$ Cópias em microfilme dos originais depositados em arquivos alemães podem ser consultados no Arquivo Histórico de Joinville, Santa Catarina.

${ }^{7}$ No início, a maioria destinava-se a esta colônia, depois denominada Joinville, com algumas observações relacionadas a Blumenau.

${ }^{8}$ Ver: 〈https://www.joinville.sc.gov.br/wp-content/uploads/2016/06/Listas-de-imigrantes-de-Joinville-de-1851-a-1891e-de-1897-a-1902.pdf〉; ou 〈https://issuu.com/sidneibjr/docs/listas_de_imigrantes_de_joinville_d/315〉. Para o período 1851 a 1866, as listas foram publicadas em versão impressa (BÖBEL; THIAGO, 2001). Este endereço inclui listas até 1905. Registra-se, ainda, a seguinte observação, realizada em seguida aos dados da ficha técnica referente à viagem de Florentin, em 17/05/1852: nos anos 1852 e 1853, os dados constantes das listas de emigrantes foram transferidos para livros da polícia portuária de Hamburgo, sem distinção de destino, omitindo dados como nomes e idades dos filhos, profissão e religião do imigrante. Os originais foram destruídos. Como só $10 \%$ destes emigrantes tinham Dona Francisca como destino, o AHJ, através do Arquivo Estadual de Hamburgo, solicitou a compilação dos emigrantes para Dona Francisca, trabalho este executado por Friedrich Boy, estudante de História da Universidade daquela cidade.
} 
publicados: ao que tudo indica, o diretor da Colônia Dona Francisca listava os imigrantes (Einwanderung Journal) ${ }^{9}$ ao deixarem os navios, antes de seguirem adiante. ${ }^{10}$ Tudo sugere que os passageiros que não constam nas listas "J" desembarcaram num dos portos de escala, começando por Lisboa e, mais verossimilmente, Rio de Janeiro ou Santos. Alguns sinais nas listas também permitem inferir que alguns navios, em vez de voltarem, seguiam em frente, para Laguna, Desterro ou Porto Alegre.

Esta documentação possibilita aproximações diversas com os temas da imigração e da colonização na segunda metade do século XIX e início do XX. Para algumas questões que as fontes permitem colocar, a presente pesquisa ateve-se ao período de 1851 a 1889, pois a última lista elaborada sob a responsabilidade da "Sociedade Colonizadora de Hamburgo" dizia respeito a dois imigrantes que desembarcaram do vapor "Laguna”, em 04 de agosto de $1890 .{ }^{11}$

\section{Conteúdo das listas}

As informações contidas nas listas traduzidas são organizadas alfabeticamente em função dos sobrenomes dos passageiros: homens que viajavam sós, geralmente solteiros; mulheres solteiras, casadas ou viúvas, que embarcaram aparentemente desacompanhadas ou na companhia de filhos, irmãos ou outros parentes; e homens chefes de família, acompanhados da esposa e, quando era o caso, de filhos, cunhadas, cunhados, irmãs e irmãos, mães, pais, etc.

Visando apresentar esses dados e o tema da presente nota de pesquisa, selecionou-se o passageiro do vapor "Rio" que constituiu tronco de importante família de industriais em Blumenau, para colocar algumas questões introdutórias. Da mesma forma, para alguns exemplos, destaca-se a lista dos passageiros do mesmo navio, no qual embarcou Hermann Hering. Assim, com a mencionada "ficha técnica", começa-se identificando a viagem deste vapor em setembro e outubro de 1878.

\section{“Ficha técnica” dos navios e das viagens}

Capitão: von Helms. Nome do cosignatário: R.O. Lobedanz. ${ }^{12}$ Data da partida, 05/09/1878. Destino: São Francisco (do Sul); data da chegada, 07/10/1878. Passageiros a bordo: 118 J (Joinville) e L (Hamburgo). Nascimentos e falecimentos a bordo (nenhum).

\footnotetext{
${ }_{9}$ Jornal da Imigração, publicado em Joinville.

${ }^{10}$ Nas listas elaboradas para publicação on-line, a notação “J” significa listas de desembarque, e “L”, listas de embarque.

${ }^{11}$ De acordo com a nota da tradutora (Elly Herkenhoff) que publicou as listas on-line: "a listagem só volta a existir a partir de 1898, já sob o controle da 'Sociedade Hanseática de Colonização', que viria a assumir a massa falida da antecessora”.

12 Consignatário: os dicionários especializados referem-se à pessoa física ou jurídica responsável pelo ingresso da mercadoria, etc. Evidentemente, a "mercadoria”, nesse caso, é a carga constituída pelos imigrantes e suas famílias.
} 


\section{Observações}

- Complementa a ficha técnica, no final da lista, registro das assinaturas autenticando o documento, tais como do diretor da Colônia e/ou do cônsul geral do Império do Brasil em Hamburgo/Lübeck/Bremen.

- Geralmente, não consta a nacionalidade do navio.

- Os registros dos consignatários iniciam-se em 06/04/1872; R.0. Lobendanz assinou as listas do período de 19/05/1876 até 20/05/1890.

- As informações a respeito dos nascimentos e falecimentos a bordo oscilam muito. Nesta viagem, como não houve falecimentos e nascimentos a bordo, o número de passageiros na lista "L" foi corroborado na lista "J".13

- Geralmente, como no caso em pauta, não estão anotados os portos de escala (presume-se que podiam ser Lisboa, Salvador [ou Bahia], Rio de Janeiro, Santos). ${ }^{14}$

\section{As variáveis}

Observação inicial: supõe-se que as informações contidas na lista são obtidas no momento do embarque, a partir de declaração do passageiro, exceto a ficha técnica, e checadas quando do desembarque.

Seguem alguns exemplos:

Vapor "MONTEVIDEO", 18/06/1880:

- Imigração “em família”. HERING, Bruno: 38 anos, lavrador, Grossröhrsdorf, Saxônia, c/ cunhada Minna (40), filhos Johanne (12), Nanni (9), Gretchen (6), Max (4), Gertrude $(3 / 4)$, protestantes, $3^{a}$ classe; $p /$ São Francisco (listas “J” $e$ “ $L$ ”).

- Imigração de homem solteiro. BARCHFELD, Justus: 28 anos, mineiro, Dortmund, Prússia, solteiro, protestante, 3모 classe (listas “"” e “L”).

- Imigração de mulher desacompanhada. RAUCH, Elisabeth: 65 anos, Langendorf, Boêmia, viúva, católica, 3a classe (listas “J” e “L”).

- Imigração de mulher acompanhada por filho menor. STARK ou STORCH, Amalie: 32 anos, Reichenberg, Boêmia, casada, c/ filho Albert (3), católicos, $3^{\underline{a}}$ classe (listas "J" $e$ “L”).

\footnotetext{
${ }^{13}$ Entretanto, em algumas travessias, o número de falecimentos foi muito importante. Gustav Hermann Strobel relata sobre o trauma causado pelos múltiplos falecimentos durante sua viagem ao Brasil (STROBEL, 2015). De fato, a ficha do navio informa que houve 35 falecimentos a bordo, entre os 212 ou 202 passageiros, conforme a contabilidade realizada, respectivamente, a partir da lista de embarque ou a lista de desembarque.

14 Esta é uma questão em aberto, pois muitas das listas dão a entender, explicita ou implicitamente, que escalas eram feitas. Todavia, Gustav Hermann Strobel, nas suas memórias, não faz nenhuma referência a paradas durante a viagem do Florentin, em 1854 (STROBEL, 2015).
} 


\section{Outras observações}

- No que diz respeito à viúva Elisabeth Rauch, foram buscadas nas listas anteriores pistas de pessoas que poderiam esperar pela imigrante em São Francisco/Joinville. Foi encontrado o passageiro Georg Rauch, que viajou em 31/05/1869 com sua mulher; na ocasião, ele tinha 37 anos, era lavrador e, como Elisabeth, católico e igualmente nascido na Boêmia. Pelos cálculos, ele teria idade para ser filho da viúva. Entretanto, não há, aparentemente, consistência dos dois locais de origem (Langendorf e Rosshaupt - hoje Rosvadov, na República Checa). 0 que se perde, nesse tipo de pesquisa, resulta da possibilidade de Elisabeth ter sido antecedida na imigração por uma filha (o sobrenome de família das mulheres geralmente não era registrado) e um genro.

- Quanto a Amalie Stark (ou Storch - as duas possibilidades podem decorrer de problemas de legibilidade no documento original), foi encontrado, numa lista anterior, o nome de Johann Stark, 36 anos, lavrador, de Johannesthal, Boêmia, solteiro, católico, e que partiu de Hamburgo em 19/09/1877, quase um ano antes. Como já mencionado em nota, o erro no estado civil é relativamente frequente. Deve se tratar do esposo, mas não foi possível uma consistência absoluta entre as informações relacionadas às duas pessoas, pois a localidade de Reichenberg não foi encontrada no mapa (lembrando, inclusive, que a Boêmia atualmente faz parte da República Tcheca). Se a hipótese de ser o esposo estiver correta, é possível descartar o sobrenome Storch que, aliás, não foi encontrado em listas anteriores.

- Adendo: mulheres solteiras e desacompanhadas. A documentação informa sobre muitas jovens nessas condições, com idades diferentes, que vieram ao Brasil. Comparando as origens dessas mulheres com as de outros passageiros no mesmo navio, é possível supor que, de fato, a maioria dessas jovens não viajava realmente sozinha.

\section{Os nomes dos imigrantes}

Como é possível depreender pelas observações anteriores, tudo indica que a transcrição dos nomes de passageiros foi realizada de forma consistente, com poucas exceções.

\section{A idade dos imigrantes}

As idades eram registradas ao lado do nome dos imigrantes, informação que praticamente se manteve durante todo o período enfocado. Nunca há menção à data de nascimento, o que permite deduzir que essas anotações foram feitas em função da declaração dos passageiros. 0 exemplo a seguir traduz possibilidade de erros nessas menções.

A pequena Gertrudes, anteriormente mencionada, teve a mesma idade ( $3 / 4)$ declarada quando da confecção da lista de embarque "L" como no desembarque "J". Imaginando que a menção signifique $3 / 4$ de ano, a menina teria nove meses; sendo assim, a criança foi concebida por volta de dezembro de 1878 , cerca de quatro meses depois da partida do pai Hermann Hering. 


\section{As ocupações ou profissões dos emigrantes}

A lista do vapor "Rio" registra 21 lavradores, seis mineiros, dois tecelões (incluindo um "fabricante de tecidos"), dois torneiros (um deles "torneiro de metais"), seis artesãos (alfaiate, curtidor, marceneiro, pintor, relojoeiro, sapateiro), além de um "condutor de máquinas". Também havia um professor de música e, viajando em primeira classe, um comerciante. Sem nenhuma análise crítica, foram listadas, para o período, 220 ocupações masculinas distintas nas listas de passageiros. Entretanto, este número deverá ser reduzido quando aplicado o resultado de um estudo a respeito de algumas profissões que, aparentemente originais, podem ser redundantes ou relacionadas a um ofício semelhante (por exemplo, britador, entalhador, moveleiro, etc.).

Como demonstrativo, apresenta-se a Tabela 1, extraída de Magalhães e Nadalin (2017).

TABELA 1

Emigrantes alemães embarcados em Hamburgo com destino ao Brasil, segundo ocupações dos adultos do sexo masculino-1851-1889

\begin{tabular}{|c|c|c|c|c|c|c|c|c|c|c|}
\hline \multirow[t]{2}{*}{ Ocupações } & \multicolumn{2}{|c|}{$1851-1859$} & \multicolumn{2}{|c|}{$1860-1869$} & \multicolumn{2}{|c|}{$1870-1879$} & \multicolumn{2}{|c|}{$1880-1889$} & \multicolumn{2}{|c|}{ Total } \\
\hline & $\mathbf{N}$ & $\%$ & $\mathrm{~N}$ & $\%$ & $\mathrm{~N}$ & $\%$ & $\mathrm{~N}$ & $\%$ & $\mathrm{~N}$ & $\%$ \\
\hline Rural & 579 & 47,82 & 1.107 & 58,98 & 782 & 63,58 & 617 & 28,94 & 3.085 & 47,83 \\
\hline Artesãos & 391 & 32,29 & 423 & 22,54 & 146 & 11,87 & 324 & 15,20 & 1.284 & 19,91 \\
\hline Comerciantes & 41 & 3,39 & 25 & 1,34 & 9 & 0,74 & 54 & 2,54 & 1.329 & 2,0 \\
\hline Ecônomos & 50 & 4,13 & 69 & 3,68 & 15 & 1,22 & 25 & 1,18 & 159 & 2,47 \\
\hline “Técnicos” (1) & 74 & 6,11 & 23 & 1,23 & 4 & 0,33 & 76 & 3,57 & 177 & 2,75 \\
\hline “Operários” & 14 & 1,16 & 167 & 8,90 & 232 & 18,87 & 884 & 41,47 & 1.297 & 20,11 \\
\hline Outros & 34 & 2,81 & 52 & 2,77 & 32 & 2,61 & 36 & 1,69 & 154 & 2,39 \\
\hline Sem registro & 28 & 2,32 & 11 & 0,59 & 10 & 0,82 & 116 & 5,44 & 165 & 2,56 \\
\hline Subtotal & 1.211 & 100,0 & 1.877 & 100,0 & 1.230 & 100,0 & 2.132 & 100,0 & 6.450 & 100,0 \\
\hline Outras origens (2) & 86 & 6,63 & 60 & 3,10 & 165 & 11,83 & 387 & 15,37 & 698 & 9,77 \\
\hline Total & 1.297 & 100,0 & 1.937 & 100,0 & 1.395 & 100,0 & 2.519 & 100,0 & 7.148 & 100,0 \\
\hline
\end{tabular}

Fonte: Böbel e Thiago (2001, p. 296-434) e Herkenhoff et al., disponível em: 〈http://www.arquivohistoricojoinville.com.br/ Listalmigrantes/lista/tudo.htm>.

(1) Entre os "técnicos", com as devidas aspas, incluem-se engenheiros, professores, pastores, militares, etc.

(2) Austro-húngaros, belgas, brasileiros, dinamarqueses, finlandês, franceses, franco-suíços, grego, ítalo-suíços, italianos, leto, poloneses, portugueses, russos, suecos, turcos.

Algumas dificuldades se colocam para a análise das ocupações, entre as quais a real possibilidade de quantificarmos a entrada de "lavradores". Concretamente, pode-se exemplificar com os registros de Paul e Bruno Hering, qualificados com esta ocupação, o que parece não passar perto da profissão original destes imigrantes. É possível, portanto, que a menção nos registros, pelo menos nesse caso, não seria rigorosa. Ou seja, muitos imigrantes poderiam ter tranquilamente declarado como ocupação o ofício de "lavrador" (Bauer), se tivessem a intenção de se radicar em Dona Francisca para desenvolverem uma atividade agrícola. Para outros, poderia ser a forma de burlar uma exigência da Sociedade, objetivando trazer trabalhadores braçais, capazes de fazer frente às duras tarefas de limpeza das matas na Colônia. 
Além disso, em função do baixo preço do lote, justificar-se-ia o investimento em terras por comerciantes, artesãos ou outros, interessados na produção, por exemplo, da cana-de-açúcar, do algodão ou café, o que pode significar que imigrantes que exerceram esse ou outro métier também embarcaram como agricultores. ${ }^{15} \mathrm{Em}$ parte, tudo isso explicaria que alguns, mais abonados (como alguns acionistas da Sociedade Hamburguesa de Colonização), tivessem essa qualidade ao imigrarem - muitos viajando, inclusive, na 1a classe. Também é provável que muitos comerciantes ingressassem, originalmente, no mundo do trabalho como artesãos, ou em outra atividade técnica.

Para ampliar e aprofundar o problema, verificamos as declarações de 121 imigrantes com ocupações duplas, 15 que denominamos urbanas-urbanas (pedreiro-canteiro, ecônomo-ferreiro, ${ }^{16}$ etc.), 105 intituladas urbanas-rurais ("lavrador-serralheiro", "lavrador-segeiro”, “lavrador-operário”, 17 "lavrador-ecônomo”, etc.), sempre aspeadas, pois, no mundo de então, até onde iam as atividades "rurais" e onde começavam as "urbanas"? Assim, o fato de as ocupações urbanas-urbanas constituírem somente $12,4 \%$ do total desses registros de dupla-ocupação parece sintomático.

No que concerne às ocupações, normalmente a documentação não informa esse dado para a maioria das mulheres, embora tenham sido anotadas, durante o período estudado, uma parteira, algumas governantas e, sobretudo para as solteiras, a profissão de criadas e operárias. Fica, ainda, o registro de que a documentação referente a alguns navios não traz essa informação.

- Criadas. Na lista do navio "Franklin”, que chegou em 19/04/1860, foi encontrado o primeiro registro anotando essa qualificação. Tem como referência o passageiro J.P. (sic) Albrecht, 30 anos, lavrador, originado de Kirchzell, Baviera; viajava acompanhado da mulher Maria (36), dos filhos Anna (4) e Josepha (2). Acompanhavam a família duas criadas, Maria (27) e Catharina (14), provavelmente solteiras. Todos os passageiros viajaram em 3 a classe e foram anotados nas duas listas, “L” e “J". A partir dessa data, portanto, este tipo de menção torna-se relativamente importante. Porém, poucas vezes foi possível vincular essas mulheres, com idades diferentes, a um determinado passageiro ou família, como nesse caso, aparentando que viajavam sozinhas.

- Operárias. Em 29 de dezembro de 1873 chegou em São Francisco o navio “Elwood Cooper”, trazendo 133 passageiros. Entre eles a viúva Dorothea Körner, protestante,

\footnotetext{
$\overline{15}$ Para uma discussão a respeito, ver Magalhães e Nadalin (2017, texto inédito). Ademais, as listas traduzidas às vezes se reportam à ocupação de "agricultor" que não esclarece nada, uma vez que, em alemão, tanto este termo como lavrador traduzem-se por "Bauer".

${ }^{16}$ A ocupação "ecônomo" (Verwalterstelle) é muito antiga, relacionada mormente à administração da Igreja. Atualmente os dicionários designam ecônomo como gestor, mordomo, administrador, despenseiro... Entretanto, surpreende o fato de que o número de ecônomos foi relativamente grande (por exemplo, maior do que comerciantes: 159 e 129 , respectivamente). Além disso, a qualidade de "ecônomo", ao que parece, exigiria certa experiência. Muitos imigrantes jovens foram registrados dessa forma, o que se soma a outras incongruências.

17 Observe-se que uma menção em listas refere-se a "operário agrícola".
} 
de Hamburgo e operária. Embora, para os homens, esse tipo de registro começa a ser corrente a partir de $1863,{ }^{18}$ foi somente depois de 1874 que começa a ser corriqueira a informação de operárias, geralmente solteiras. 0 primeiro registro de tal profissão para um imigrante é de 1852, mas os operários homens começam a proliferar nas listas a partir de 1863, quando as estatísticas passam a se tornar importantes.

- Imigrantes abonados? A história da imigração geralmente tem como referência a vinda de estrangeiros pobres, expulsos pela miséria do país natal. Entretanto, uma análise detida nas listas de passageiros permite vislumbrar o contrário. Como exemplo, tem-se a família de Gustav Stutzer, que viajou no vapor “Uruguay”, em agosto de 1885, juntamente com 148 passageiros a bordo. 0 documento informa que ele tinha 46 anos ao viajar e era um "diretor”, originário de Goslar, Prússia, ${ }^{19}$ acompanhado de sua mulher Theresie (43) e dos filhos Nina (19), Käthe (18), Gertrud (16), Therese (14), Ilse (12) e Eva (2), todos protestantes. Viajavam em 1a classe, com uma bagagem de 116 volumes. Acompanharam a família Emilie Strecker (23), governanta, e a criada Louise Pfenning (ou Pfennig - 19). Igualmente acompanhando, mas viajando na 3a classe, estavam Louise Billhardt (24) e o criado August Rösling (25). Também consta como acompanhante o agrônomo Max von Klitzing (todos registrados nas listas "J" e "L"). ${ }^{20}$

\section{Lugares de origem}

Algumas pesquisas mostram que, de modo geral, as indicações do local de origem nos documentos estão corretas, apesar da possibilidade da duplicação de alguns topônimos. Por outro lado, notam-se algumas incongruências. Por exemplo, Hermann Hering teria sido, como seus filhos, oriundo de Dresden, na Saxônia. Seu irmão, de Grossröhrdorf, uma localidade distante a $30 \mathrm{~km}$, provavelmente na região dominada pela mencionada cidade. Dependendo do uso dessa variável, a diferença pode ser ou não importante.

o problema é mais grave quando atentarmos para as modificações do mapa da Alemanha a partir, principalmente, da expansão da Prússia. Assim, quando um emigrante declarava ser "prussiano", o que ele queria realmente informar? De fato, poderia ter nascido próximo de Berlim, ou na Pomerânia, ou, mesmo, no antigo reino de Hanover (região de origem de muitos imigrantes); ou seja, uma superestimação de prussianos nas listas de imigrantes pode levar à perda de ricas estatísticas. 0 Gráfico 1 mostra, por exemplo, a influência da formação do império alemão em 1870 nos registros das origens

\footnotetext{
18 Por exemplo, em 1872, a porcentagem de operários homens na documentação era de $29,6 \%$ e, em 1873, 12,3\%.

${ }^{19}$ Salvo a Wikipédia, ainda não foi encontrada outra referência a esse que viria a ser nome de rua em Blumenau: nasceu em 1839 e faleceu em Heidelberg em 1921, tendo ficado no Brasil pelo menos até 1909. Foi pastor evangélico, teólogo e escritor (sua mulher também).

${ }^{20}$ Todos os acompanhantes de Gustav Stutzer estão, também, registrados independentemente nos documentos “J” e "L" - como, aliás, é norma nesses casos. Todavia, não foi encontrada nenhuma outra referência ao agrônomo Max Von Klitzing nesta lista - portanto, não se sabe em que classe viajou, nem sua origem. Por outro lado, a listagem traz o nome, sem vinculação com os Stutzer, de Louis Rother (50), igualmente agrônomo e também originado de Goslar, Prússia: era solteiro e viajou na 3ํㅡㄹ classe (listas "J" e "L").
} 
dos migrantes. Da mesma forma mostra uma tendência, antes de 1870, de aumento nas declarações dessa origem.

\section{GRÁFICO 1}

Participação dos imigrantes prussianos no total de imigrantes alemães no período - 1851-1889

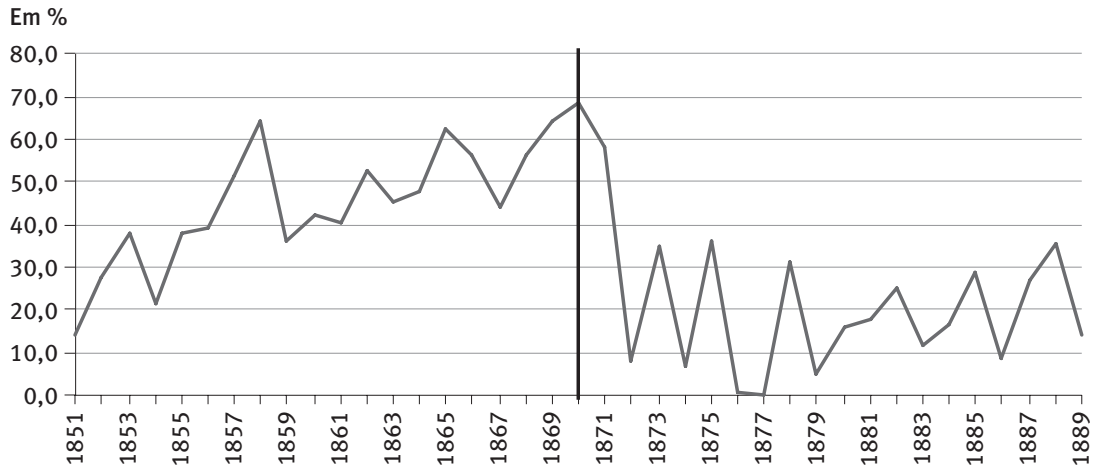

Fonte: Listas de passageiros embarcados em Hamburgo com destino a São Francisco do Sul, SC.

\section{Outras variáveis}

- Bagagem dos passageiros (carga sob a responsabilidade dos passageiros). A partir de maio de 1881, algumas listas informam o número de "volumes" que cada passageiro trouxe ao imigrar.

- “Classes" de passagens. Normalmente, as passagens são de duas classes, a primeira e a terceira (segundo algumas notações, referentes a passageiros que viajavam na “entrecoberta" 21 do navio), mas isso não significa que todas as listas trazem este registro. Numa primeira observação, verificou-se que muitos passageiros que viajaram na 1a classe só estavam registrados numa lista "L", o que significa que teriam desembarcado num porto de escala. Foi o caso de um companheiro de Hermann Hering, Adolf Hürlimann (30), comerciante suíço, que pode ter desembarcado no Rio de Janeiro. Aliás, algumas indicações mostram que, pelo menos para alguns navios, São Francisco do Sul também era uma escala.

- Religião. Católicos ou protestantes, ${ }^{22}$ embora, para algumas listas, não constasse a religião.

- Destino. A maioria dos passageiros, no início do período, dirigia-se à Colônia Dona Francisca. A partir de certo momento, aparecem menções a outros destinos, como

\footnotetext{
${ }^{21}$ Considera-se a "coberta" ou a "ponte" cada um dos pisos do veleiro. A "entre-coberta" (ou "entre-forro") constitui o espaço entre duas cobertas de navio. Joaquim da Costa Leite (1991, p. 742), num artigo sobre o transporte de emigrantes portugueses, informa que "os veleiros de carreira do Brasil eram, na sua maior parte, embarcações de 200 a 400 toneladas, capazes de transportar entre 100 a 200 pessoas. Como passageiros de proa, os emigrantes não tinham acomodações próprias e dormiam no chão de um porão atravancado, escuro e sufocante".

${ }^{22}$ A única exceção anotada diz respeito a vários membros da Comunidade Herrnhuter (Irmãos Morávios), que, ao que tudo indica, dirigiram-se a Joinville, depois de desembarcados do navio Hamburg, em 29 de junho de 1886.
} 
Blumenau, São Bento e Itapocu. No entanto, em várias listas existem referências à “remigração" para Curitiba, a título de observação do tradutor. De outro modo, também há menções de que passageiros teriam desembarcado antes de chegarem a São Francisco do Sul (Rio de Janeiro, Santos, etc.); outros foram a Desterro e mesmo Porto Alegre, ou, simplesmente, “foram embora”. E muitos, não sabemos quantos, voltaram para a Alemanha (o caso de Gustav Stutzer, antes citado). Outros, finalmente, foram à Europa a negócios ou a passeio.

\section{Para concluir}

No período em destaque (1851-1889), chegaram no Brasil 65.614 alemães e 5.207 suiços, para um total de 939.771 imigrantes. ${ }^{23}$ Destes, 7.102 entraram no Brasil pelo porto de São Francisco do Sul, constituindo um epifenômeno da colonização, planejada em especial para a cafeicultura paulista.

Na descrição e crítica das listas de passageiros, procurou-se deixar implícita a riqueza dessas fontes. Sem mencionar a natural vocação do demógrafo em buscar dados quantitativos relacionados à imigração por idade, sexo e estado civil, o historiador também será atraído para as possibilidades abertas pela documentação.

Quanto às ocupações dos emigrantes e/ou dos imigrantes, de fato esta é uma questão ainda a ser esclarecida, pois não se sabe, como foi mencionado no texto, até que ponto a declaração da profissão era feita no intuito de atender a uma demanda da Sociedade Hamburguesa de Colonização ou, mesmo, das políticas de imigração do Estado brasileiro.

Da mesma forma, muito embora a própria análise crítica da documentação tenha mostrado a impropriedade da démarche, ainda é possível buscar, entre as mulheres que aparentemente vieram solteiras e desacompanhadas, aquelas que realmente viajaram sozinhas. Não será uma pesquisa fácil e resultados bem concretos também serão difíceis: o ideal seria articular essa documentação com os registros de batismos, casamentos e óbitos nas diversas colônias para onde se dirigiram os imigrantes. Mas essa será uma pesquisa para outra vida.

\section{Referências}

BÖBEL, M. T.; THIAGO, R.S. Joinville, os pioneiros: documento e história - 1851 a 1866. Joinville: UNIVILLE, 2001.

BÖBEL, M. T. A ótica da tradutora. In: BÖBEL, M. T.; THIAGO, R. S. Joinville, os pioneiros: documento e história - 1851 a 1866. Joinville: Univille, 2001. p. 13-15.

\footnotetext{
${ }^{23}$ Neiva e Carneiro (1950). É preciso considerar com cuidado as estatísticas oficiais, uma vez que os imigrantes viajavam com passaportes fornecidos por Estados - em especial da Europa central -, que poderiam agregar várias nacionalidades (alemães, austríacos, russos, etc.). No que diz respeito à Dona Francisca, as fontes registram, naturalmente, uma maioria de alemães (e suíços), mas havia austríacos não germânicos (da Galícia, Ucrânia, Hungria, etc.) e outras nacionalidades que também entravam por este porto.
} 
LEITE, J. da C. O transporte de emigrantes: da vela ao vapor na rota do Brasil, 1851-1914. Análise Social, v. 26, n. 112-113, p. 741-752, 1991. Disponível em: 〈http://analisesocial.ics.ul.pt/ documentos/1223042291X2sKU1fe9Ma04BB1.pdf〉. Acesso em: 25 out. 2018.

MAGALHÃES, M. D. B. DE; NADALIN, S. O. Imigração germânica, etnicidade e identidade profissional. Colonização em Joinville (Dona Francisca), Província de Santa Catarina. 1851-1889. (Universidade Federal do Paraná, 2017 - artigo aceito para publicação na Revista UNESP História).

MALHEIROS, A.Tempo ao tempo: nasce um museu. Blumenau: Contraponto, 2011.

NEIVA, A. H.; CARNEIRO, J. F. Movimento imigratório no Brasil de 1819 a 1947. In: CARNEIRO, J. F. Imigração e colonização no Brasil. Rio de Janeiro: Faculdade Nacional de Filosofia, 1950.

REINHARD, M.; ARMENGAUD, A.; DUPÂQUIER, J.Histoire génerale de la population mondiale. Paris: Montchrestien, 1968.

SCHNEIDER, J. Emigração alemã para o Brasil - 1815/1870. III Colóquio de Estudos TeutoBrasileiros. Porto Alegre: Editora da URGS, 1980. p. 77-106.

STROBEL, G. H. Memórias de Gustav Hermann Strobel: relatos de um pioneiro da imigração alemã no Brasil. 2. ed. Curitiba: Instituto Memória, 2015.

\title{
Sobre o autor
}

Sergio Odilon Nadalin é licenciado em História (UFPR), mestre em História do Brasil (UFPR) e doutor em História e Geografia das Populações (EHESS). Professor aposentado, colaborador no Programa de Pós-Graduação em História da Universidade Federal do Paraná (UFPR), bolsista de produtividade sênior no CNPq.

\section{Endereço para correspondência}

Rua Bororós, 555

80320-260 - Curitiba-PR, Brasil.

\begin{abstract}
Heading to America: passengers of the Hamburg-São Francisco del Sul route in the second half of the 19th century.
\end{abstract}

The purpose of this text is to critically present a set of documents related to immigration. The lists of passengers who boarded in Hamburg and landed in São Francisco do Sul, Santa Catarina, between the years 1851 and 1889, translated to Portuguese, whose original documents are part of the Historical Archive of Joinville, SC. Basically, the contents of these sources include the "factsheets" concerning each vessel and each trip, the passengers' names (including names of family members and other accompanying persons), age, profession, place of origin (usually place of birth), marital status (when applicable), religion, and various observations noted by translators.

Keywords: History of migrations. Sources. German immigration. Colonization. 


\section{Resumen}

Rumbo a América: pasajeros de la ruta Hamburgo-São Francisco del Sul en la segunda mitad del siglo XIX

El presente texto tiene por objetivo presentar críticamente un conjunto de documentos que hablan sobre la e/inmigración. Se trata de nóminas de pasajeros embarcados en Hamburgo y que desembarcaron en São Francisco del Sur, Santa Catarina, entre 1851 y 1889, traducidas al portugués, cuyos originales forman parte del acervo del Archivo Histórico de Joinville, Santa Catarina. Básicamente, el contenido de estas fuentes incluyen las fichas técnicas de cada navío y el viaje concerniente, los nombres de los pasajeros (y en algunos casos el nombre de sus familiares u otros acompañantes), su edad, profesión, proveniencia (generalmente local de origen), su estado civil (cuando era el caso), religión y observaciones diversas de los traductores.

Palabras clave: Historia de las migraciones. Fuentes. Inmigración alemana. Colonización.

Recebido para publicação em 08/11/2018

Aceito para publicação em 13/11/2018 